\title{
Una doble argumentación en favor de la definición utópica de América: "El presagio de América" de Alfonso Reyes
}

\section{Eugenia Houvenaghel}

Universiteit Gent

Fondo de Investigaciones Científicas-Flandes

\section{INTRODUCCION}

En su ensayo "El presagio de América", Alfonso Reyes se ocupa del acontecimiento histórico príncipe del Nuevo Mundo. El Descubrimiento y la génesis del Descubrimiento constituyen temas muy polémicos en la historiografía de Hispanoamérica². Quinientos años después de la fecha en que Colón llega a tierras americanas, la empresa del genovés todavía es considerada de forma diversa por los historiadores, tal y como lo demuestra la variedad de nombres con que ha sido bautizada su obra: Descubrimiento o encubrimiento, invención o invasión, hallazgo o tropezón, encuentro o mutuo Descubrimiento. Los viajes de Colón son considerados desde puntos de vista diferentes: para unos significa el inicio de la conquista y, con ello, del proceso de colonización de América y para otros supone la creación de un mundo utópico.

Se discute, asimismo, cuál era el proyecto de Cristóbal Colón al emprender su viaje en 1492. ¿El proyecto asiático o el americano? El proyecto asiático consistiría en descubrir un nuevo camino por el occidente hacia las Indias. El proyecto americano, en descubrir una tierra nueva. Hoy en día, la mayoría de

1"El presagio de América”, Ultima Tule, O.C. t. XI: 11-62. En adelante abreviaremos: PA.

${ }^{2}$ Véase La idea del descubrimiento de América, de O'Gorman (1976), una “historia” de la historia del Descubrimiento. Marcel Bataillon (1955) opone las dos principales concepciones del Descubrimiento de América; Fernández Retamar (1989) comenta la discusión sobre el tema. 
los historiadores sostienen que la intención de Colón era llegar a las Indias y que solamente por casualidad tropezó con un nuevo continente. Otros, una minoría, afirman que la intención principal de Colón era descubrir un nuevo continente, pero lo mantenía en secreto para no arriesgar el éxito de su empresa.

En nuestro análisis, nos vamos a interesar por la posición que Reyes va tomando en el debate histórico acerca del Descubrimiento de América. El texto titulado "El presagio de América", según declara Reyes prudentemente en la parte introductoria, tiene el objetivo de aventurar una hipótesis sobre el sentido de los antecedentes del doce de octubre. Sin embargo, el ensayista no resume cuál es su tesis histórica; antes bien enfatiza que no ambiciona realizar un estudio exhaustivo del tema de su interés, sino que sólo pretende, modestamente, exponer su visión de los hechos:

Las páginas que aquí recojo adolecen seguramente de algunas deficiencias de información, a la luz de investigaciones posteriores, y ni siquiera aprovechan todos los datos disponibles en el día que fueron escritas. Pero ni tenía objeto entretenerse en la reiteración de datos que transformara en investigación erudita lo que sólo pretende ser una sugestión sobre el sentido de los hechos, ni tenía objeto absorber las nuevas noticias si, como creo, la tesis principal se mantiene. Además, el que pretende decir siempre la última palabra, cuando la conversación no tiene fin, corre el riesgo de quedarse callado (PA: 12).

Nos ocuparemos, en este capítulo, de uno de los aspectos más llamativos del ensayo y que, extrañamente, no ha sido investigado hasta ahora: la relación entre el fondo y la forma en esta argumentación de Alfonso Reyes. Lejos de optar por un texto ininterrumpido y homogéneo en discurso expositivoargumentativo, el ensayista prefiere una forma fragmentada en 21 breves capítulos subtitulados en los que alterna descripción, narración, diálogo, exposición y argumentación ${ }^{3}$. Trataremos de sacar a la luz la argumentación subyacente a la forma fragmentada y variada del ensayo, así como de reconstruirla y darle coherencia.

${ }^{3}$ Un interesante punto de comparación, bajo una perspectiva formal, para este ensayo de Alfonso Reyes lo constituye el libro América en Europa de Arciniegas (1975). El ensayista colombiano defiende una tesis muy parecida a la de Reyes en la parte "El continente presentido" justamente porque el texto de Arciniegas, una narración cronológica, es mucho más homogéneo desde un punto de vista formal que el ensayo histórico de nuestro autor. 


\section{UN LOGRO ESTILISTICO QUE DESVIA LA ATENCION DE LA TESIS HISTORICA}

Es preciso atraer la atención sobre el hecho de que "El presagio de América” no debe leerse como un alegato en favor de una determinada tesis sobre la génesis del Descubrimiento. El tono que caracteriza el ensayo dista mucho de ser austero y sobrio; por el contrario, en sus páginas hallará el lector una amena y entretenida disertación, que no da la impresión de ser construida sobre la base de un esquema argumentativo. Este logro estilístico basa su eficacia, principalmente, en la feliz y sabia combinación de la exposición histórica con pequeñas narraciones, descripciones o diálogos llenos de fantasía y encanto, por un lado, y en la fragmentación del texto en 21 breves capítulos más o menos independientes, por otro. Al margen de estas estrategias formales, cabe mencionar que el gran número de figuras estilísticas empleadas contribuye a confirmar la impresión del lector de que se trata de un texto rico y variado, a la vez informativo y poético, mucho más que de un ensayo con una unívoca y bien determinada orientación persuasiva.

La exposición histórica domina grandes partes del texto, momentos en los que Reyes explica el curso de los acontecimientos, apoyando su discurso en diversas y variadas fuentes de investigación y documentación. El autor prevé las diferentes propuestas de los historiadores y subraya, según el caso, el carácter científico o más bien fantástico de las diferentes teorías e hipótesis. El análisis de los acontecimientos históricos le lleva, por ejemplo, a criticar la "deificación” de Colón, a aclarar la confusión entre el Descubrimiento propiamente tal y los orígenes americanos, a contradecir la hipótesis según la cual los indios peruanos ya conocían al hombre europeo antes de la llegada de Pizarro o a negar la rivalidad entre Colón y Vespucio...

Pues bien, lo interesante, desde un punto de vista formal, es que Reyes alterna la información geográfica e histórica, las hipótesis de los diferentes historiadores y el análisis y la crítica personal respecto a dichas teorías, con narraciones como la siguiente en la que refiere cómo Leif Ericson, hijo de Erik el Rojo, fue uno de los primeros europeos en llegar a Vinlandia (América del Norte) alrededor del año 1001:

De allí, como Noé soltaba sus aves desde el Arca, enviaron al interior sus corredores escoceses, que tenían nombre de caballos, y Hake y Hekia regresaron algún tiempo después trayendo haces de trigo y racimos de uvas, símbolos de los dones del suelo. Más al Sur encontraron una gran bahía, una isla de difícil acceso poblada de negros parecidos a los africanos, quienes navegaban en barcas de pieles y consintieron en trocar con ellos algunas mercaderías. Parece que vivían en cavernas y su estado era de lo más primitivo (PA: 23). 
$\mathrm{Al}$ margen de estas pausas narrativas históricas, que disipan el prescindible rigor de un texto expositivo, con cierta regularidad, el ensayista introduce anécdotas y relatos ficticios. Así, en cierto punto, menciona el cuento "DonogooTonka" de Jules Romains (1960), cuyo personaje principal es un eminente profesor de geografía que describe, en uno de sus libros científicos, una región de minas auríferas situada en Sudamérica y que responde al nombre de Donogoo. Los datos son erróneos y la región no existe. Este error arruina la reputación científica del profesor Le Trouhadec. Sin embargo, gracias a la credulidad de los aventureros y buscadores de oro, Le Trouhadec consigue convertir la región imaginaria en realidad y, de este modo, es reivindicado como una autoridad en el área de geografía. Es evidente que esta pequeña narración no sólo ofrece al lector un divertimiento, sino que también sostiene la tesis de Reyes, según la cual la ficción, el mito, esto es, la "mentira", ejercen un considerable impacto sobre la realidad.

Entre los pasajes descriptivos, que interrumpen la exposición y el análisis históricos, citemos el siguiente en el que el ensayista ofrece detalles divertidos y sumamente plásticos acerca de los seres fantásticos que pueblan la utopía del cardenal de Aliaco:

Según él, hay los que comen peces crudos y sólo beben agua de mar, y hay los que aúllan como perros en vez de articular palabras; hay Cíclopes, hay Amazonas; hay los que tienen un solo pie que, cuando se acuestan, les sirve de sombrilla; hay hombres acéfalos y otros con los ojos en la nuca; y hay los dulces ribereños del Ganges que mueren al más leve olor repugnante y se nutren con el aroma de las frutas (PA: 42).

El ejemplo más claro, en "El presagio de América", de esta tendencia a intercalar estructuras variadas que, en algunos casos, incluso, llegan a vencer el predominio de la exposición histórica, lo constituye la pequeña "comedieta de Colón” (PA: 35-40), una conversación ficticia entre Martín Alonso Pinzón y Cristóbal Colón, en la que el ensayista imagina un diálogo entre ambos viajeros. Este diálogo, como era de esperar, viene a confirmar la tesis expuesta, más arriba, por Reyes, según la cual el genovés buscaba aquel paraíso de abundancia y felicidad del que hablaban las leyendas de la Antilia, y no una nueva ruta hacia el Oriente o Cipango, inspirado en los relatos de Marco Polo sobre Cathay, el imperio legendario del Gran $\mathrm{Kan}^{4}$ o sobre la isla de Cipango, rica en oro y piedras preciosas. He aquí un pequeño fragmento de este ameno diálogo ficticio:

${ }^{4}$ Marco Polo, Il Millione (1290). Cathay (China) y Cipango (Japón) serán obsesiones colombinas: Colón acaba por pensar que Cuba es Cathay y en un primer momento, confunde Cuba con Cipango (Pastor 1983: 52; Penrose 1960: 30). 
-Andáis empeñado, Cristóbal, en descubrir una tierra nueva. [...] no acabo de persuadirme que hayáis caído en esos desvaríos de la Antilia.

-¿Queréis que os lo repita? Papeles, libros, conversaciones de prácticos, las noticias que recogí durante mi corto viaje a Guinea, ¿os parece todo desatino? ¿Pues de qué otro modo se aprenden las verdades? ¿No se descubrieron así Porto-Santo y Madera? Yo os digo que, al Occidente de las Islas Canarias y del Cabo Verde, hay todavía mucha tierra por descubrir, y que aquí daremos con la Antilia, donde en otro tiempo se refugiaban los portugueses perseguidos, la isla de las Siete Ciudades que ponen las antiguas cartas y el Globo de Behaim. Y si he disimulado mis esperanzas, lo hice aconsejado justamente por vos [...] Y ahora os pregunto yo a mi vez: ¿Qué tiene de más vuestro Cipango que mi Antilia? (PA: 37-38).

Resulta evidente que esta conversación, pese a ser una ficción, funciona como un alegato en favor de la tesis defendida por Reyes en "El presagio de América". Esta finalidad de la "comedieta" se torna más perceptible cuando Colón explica el verdadero significado de lo que, entre historiadores, se considera la prueba de que Colón pensaba encontrar una nueva ruta al Oriente, a saber, la carta que llevaba consigo y que había sido dirigida al Gran Kan por los Reyes Católicos.

Si el lector no se da cuenta de la orientación argumentativa unívoca del ensayo "El presagio de América", ello no sólo tiene que ver con la variación de los tipos de discurso, que acabamos de comentar, sino también con la fragmentación del ensayo en 21 breves capítulos. Cada capítulo constituye una reflexión independiente, con un inicio y un fin, sobre un problema o aspecto particular de la génesis del Descubrimiento. Entre los temas tratados por Reyes citemos, a modo de ejemplo, la cuestión de saber si los chinos han estado en América, el posible viaje de los escandinavos al Nuevo Mundo, el interés de los humanistas por estudios geográficos, la recuperación de la leyenda de Atlántida, los primeros viajes de exploración domo precedentes del viaje de Colón ${ }^{5}$, el proyecto de Colón, la contribución de los Pinzón al Descubrimiento, los viajes de Américo Vespucio, el bautismo de América. En cada capítulo, Alfonso Reyes combina varios tipos de discurso: relata, describe y comenta los hechos al tiempo que los explica y analiza. El orden de los capítulos sigue más o menos el orden histórico de los acontecimientos que han llevado al doce de octubre. Nuestro ensayista, antes de ofrecer una larga y aburrida exposición, divide su relato en apartados sueltos, disposición que le permite al lector tomar varias pausas a lo largo de la lectura, constituidas por el tránsito de uno a otro

${ }^{5}$ Para una lista y un comentario de los contactos transatlánticos anteriores al viaje de Colón, consúltese Ramos (1972). 
capítulo. En resumen, la división del ensayo en pequeñas partes hace que el texto, en su globalidad, no se lee como un relato continuo de firme orientación argumentativa sino más bien como una serie de pensamientos y consideraciones sobre el episodio histórico del Descubrimiento y sus antecedentes.

Finalmente, conviene subrayar que varias fórmulas poéticas y figuras estilísticas contribuyen a convertir la lectura de "El presagio de América" en un placer sumamente grato. Personificaciones como "la Tierra cuchicheaba al oído de sus criaturas los avisos de su forma completa" (PA: 13) o "la cara de la Tierra se va completando rasgo a rasgo" (PA: 15), alternan con bellas metáforas y comparaciones, tales como "las noticias dispersas, que al principio eran meras curiosidades, se resuelven en una sinfonía de inquietudes" (PA: 15); “[Colón] ni en esto y otras muchas cosas hacía más que colar el río de una tradición secular, para quedarse con las arenas de oro" (PA: 17); "en este ambiente, cargado ya de todos los elementos necesarios, entra la oportuna mano del mago, dibuja unos pases en el aire, funde y concreta las inefables partículas dispersas y ofrece, en la palma, la moneda [del Descubrimiento]" (PA: 30) o "las ideas geográficas flotan en el aire como partículas de polvo" (PA: 16). Al margen de este lenguaje rico en imágenes, Reyes se sirve de una prosa febril, caracterizada por estructuras rítmicas, como las siguientes: "el presagio [de América] se lee en todas las frentes, brilla en los ojos de los navegantes, roba el sueño a los humanistas y comunica al comercio un decoro de saber y un calor de hazaña" (PA: 14); "enfocando la mirada a Colón, podemos contemplar toda una muchedumbre de sabios y de prácticos, de cuerdos y locos, que lo preparan, lo ayudan y lo siguen" (PA: 16-17); "el trabajo estuvo bien compartido: unos soñaron con el Nuevo Mundo, otros dieron con él, otros lo recorrieron y trazaron, otros lo bautizaron, otros lo conquistaron, otros lo colonizaron y redujeron a la civilización europea, otros lo hicieron independiente" (PA: 57).

En definitiva, en su globalidad, "El presagio de América" es un ensayo extremadamente cuidado y variado desde el punto de vista estilístico. No hay lugar a dudas de que la belleza y variación formal puede considerarse como un factor que cautiva al lector y, en consecuencia, desvía la atención de la argumentación subyacente que comentaremos con más detalle en el siguiente capítulo de nuestro análisis.

\section{ANALISIS DEL ESQUEMA ARGUMENTATIVO SUBYACENTE}

A pesar de las apariencias, lo que Reyes está haciendo en su ensayo "El presagio de América" puede resumirse como la defensa, sobre la base de una interpretación del episodio histórico de la génesis del Descubrimiento, de una definición 
utópica del Nuevo Mundo ${ }^{6}$. En el contexto de semejantes alegatos, Perelman (1994, \$\$ 50 y 333) señala que toda argumentación en favor de un determinado concepto suele iniciarse con la enumeración de dos o más acepciones posibles del término, tras lo cual el orador escoge una de ellas como la única definición satisfactoria. Don Alfonso respeta, en líneas generales, este esquema argumentativo, al proponer, inicialmente, dos definiciones de América.

Así, existe, por un lado, una configuración geográfica o científica que, en combinación con la necesidad económica, impulsa hacia la exploración de tierras desconocidas. Y, por otro, alude a la existencia de una prefiguración imaginaria o literaria de América, que adquiere su consistencia bajo la forma de mitos y leyendas de carácter utópico. Ambas acepciones tienen su origen en la doble concepción europea sobre este continente, de manera que se puede afirmar que Reyes basa su definición de América en una configuración europea del Nuevo Mundo, esto es, en el modo en que la civilización europea del siglo XVI prefiguraba las tierras todavía desconocidas. De esta doble concepción europea sobre América, cabe inferir una doble definición del continente: en efecto, el Nuevo Mundo puede verse bien como una realidad científicogeográfica, bien como el resultado de un presagio mítico-utópico ${ }^{7}$. Ahora bien, Alfonso Reyes (PA: 12) considera la definición positivista de América como incapaz de dotar de significado al Nuevo Mundo y presenta los frutos del imaginario europeo, esto es, la definición mítica de América, como la única operativa y satisfactoria ${ }^{8}$. Veamos ahora cómo Reyes justifica el hecho de que sólo la utopía puede arrojar luz sobre el verdadero sentido del Nuevo Mundo y, en esta línea, legitimar como válida su definición de dicho continente.

Con el fin de justificar la definición utópica de América, Reyes subraya, en primer lugar, la relación causal que se establece entre el mito y el Descubrimiento de América. Para ello, recurre a un razonamiento que Perelman (1994, $\$ \$ 54$ y 353) denomina argumento de la transitividad. Este procedimiento lógico plantea que, si existe la misma relación entre los términos $\mathrm{A}$ y $\mathrm{B}$ que entre los términos $\mathrm{B}$ y $\mathrm{C}$, es lícito concluir que esta relación también se establecerá entre A y C. En el caso concreto que nos ocupa, A podría identificarse con el mito utópico, el humanismo estaría representado por $\mathrm{B}$ y, finalmente, $\mathrm{C}$ vendría a ser (el Descubrimiento de) América.

${ }^{6}$ Véase por ejemplo PA: 11-12, 58, 60. Para una lista de las utopías del Descubrimiento, consúltese Gil (1989).

${ }^{7}$ Cfr. PA: $17,25,29,60-61$.

${ }^{8}$ En esta preferencia de lo espiritual sobre lo material se reconoce el ideario de Rodó, cuya influencia constituye una constante en toda la doctrina americanista de Alfonso Reyes. 
Comenzaremos por analizar la relación entre A y B, esto es, entre el mito utópico y el humanismo. Una simple ojeada basta para reconocer que Reyes enumera, en orden cronológico, una gran cantidad de relatos míticos, todos ellos frutos de una larga tradición en la cultura occidental. La leyenda egipcia de Anubis ${ }^{9}$, de la Atlántida ${ }^{10}$, Ultima Tule ${ }^{11}$, Brandán y la Isla de los Pájaros ${ }^{12}$, la isla de las Siete Ciudades ${ }^{13}$...

Estos y otros mitos sobre diversas tierras vírgenes (PA: 12-13, 17), explica nuestro ensayista, fascinaron a los humanistas y los estimularon hacia la recuperación de las viejas utopías y, en particular, de los relatos clásicos. En efecto, el estudio de los mitos les llevará, irremisiblemente, a creer en la existencia real

${ }^{9}$ Anubis, el dios egipcio de la muerte, encargado de conducir las almas de los difuntos al más allá, "presidía a los muertos en alguna misteriosa parte del Occidente" (PA: 12).

${ }^{10}$ Platón relata en su Timeo (1966: 41-43) y en el fragmento inconcluso de Critias (1966: 279-307) la antigua leyenda de la Atlántida, según la cual, el imperio de Poseidón, habiendo sido destruido por la poderosa Atenas, se sumergió en el Mar de Sargazos. Pueden consultarse testimonios de marineros relacionados con restos de la Atlántida en el mar (Babcock 1922: 3, 23-32). Durante los siglos XV y XVI, varias islas (como la Antilla y el Brasil) figuraron, en los mapas, como restos de este continente perdido (Penrose 1960: 12-13).

${ }^{11}$ Séneca predice, en la tragedia Medea, el descubrimiento de un nuevo mundo, al que denomina la Ultima Tule: "Tiempos vendrán", sentencia el filósofo (1953: 261), "al paso de los años en que suelte el océano las barreras del mundo y se abra la tierra en toda su extensión y Tetis nos descubra nuevos orbes y el confín de la tierra ya no sea Tule". Sobre Séneca y el presagio de América, véase el artículo de Aínsa (1987: 7-26). Tule es también el nombre que Colón ha dado a Islandia en 1477 (Ballesteros Berreta 1945: 293).

${ }^{12} \mathrm{~A}$ partir del siglo VI y durante toda la Edad Media, son varias las leyendas que circulan sobre un santo irlandés, llamado Brandán (Brenainn, Brendan) y cuyo viaje, en la época del primer cristianismo, le lleva a mares fantásticos y a islas encantadas. Una de estas islas utópicas recibe el nombre de la Isla de San Balandrán o la Isla de los Pájaros. Reyes (PA: 13) menciona La Isla de los Pingüinos, un libro de Anatole France, publicado en 1908 e inspirado en la antigua leyenda de San Brandán. En el relato fantástico de A. France asistimos a la aventura de San Maël, quien se encuentra con una comunidad de pingüinos en la antigua península Armoricana (Bretaña). Los pingüinos se transforman en hombres y, a continuación, la nación Pingüinia le sirve de pretexto al autor para exponer, de modo satírico, la historia de Francia. En el libro de France resultan evidentes los ecos de Rabelais, de Montaigne, de Voltaire, de Swift y de los clásicos griegos.

${ }^{13} \mathrm{~A}$ la Isla de las Siete Ciudades, a menudo, se alude con el nombre de Antil (Antilia, Antilla, Antiglia) y, menos frecuentemente, con el nombre de Brazil. De la leyenda sobre esta isla existen varias versiones. Según una de las versiones, siete obispos españoles huyen de la España conquistada por los árabes, mientras que otra variante afirma que se trataba más bien de obispos portugueses, defensores de Mérida. En todo caso, ambas versiones coinciden en el descubrimiento, por parte de los siete obispos, de una maravillosa isla, en aguas del Océano Atlántico, sobre la que fundan siete ciudades (Babcock 1922: 71-74; Penrose 1960: 13). 
de un continente desconocido: "Los humanistas se dan a estudiar y a traducir a Platón, Teopompo, Plutarco, Aristóteles, Tolomeo, Estrabón. Y en ellos encuentran aquella noción de una tierra desaparecida, llamada Atlántida, noción que lentamente fue ganando algún crédito". (PA: 28) De este modo, concluye Reyes, "la Atlántida, resucitada por los humanistas, trabajó por América” (PA: 17). Hemos llegado, pues, a elucidar el primer paso de nuestro análisis, el que establece una relación causal entre A (el mito utópico) y B (el humanismo).

El siguiente paso en esta argumentación lógica será el establecimiento de una relación causal entre $\mathrm{B}$ y $\mathrm{C}$, esto es, entre el humanismo y el Descubrimiento de América. Para ello, Reyes nos informa de cómo los viajeros del siglo XV llevaban a cabo exploraciones, bajo las directrices, justamente, de los humanistas y cita, en apoyo de su argumentación, tres casos particulares de viajeros estimulados por el espíritu del humanismo: Buondelmonti, Niccolo de Conti y Ciriaco Pizzicolli d'Ancona. Las huellas de los mencionados relatos míticos parecen rastrearse, también, en los mapas confeccionados durante el siglo XV. Como señala Reyes, "el relato de Platón influye sobre los exploradores y cosmógrafos del siglo XV" (PA: 128) y "los viajeros no humanistas por profesión parecían moverse bajo las instrucciones expresas de los humanistas" (PA: 29).

En opinión de Reyes (PA: 13, 29, 30, 41,42) esta ingente obra humanística en torno a los mitos utópicos ejerció una notable influencia sobre Colón: el genovés conoció al Ymago Mundi del cardenal de Aliaco, la Historia rerum del Papa Pío II, Il Millione de Marco Polo, Travels de Sir John Mandeville y Le livre du chemin de lonc estude de Cristina de Pisan, todas ellas obras sobre países imaginarios ${ }^{14}$. Así, Pedro de Aliaco se refiere, en su Ymago, a lugares fabulosos donde habita gente bondadosa, de vida ilimitada. Marco Polo, por su parte, explica los aspectos sociales y políticos de la lujosa corte del Rey Gran Kan. En el libro de Mandeville, sobre un imaginario viaje por Oriente, se alude al Rey de Campa o Cochinchina, y se afirma que posee catorce mil elefantes y mil

${ }^{14}$ Ymago Mundi o Tractatus de Imagine Mundi, cardenal Pedro de Aliaco (Pierre d'Ailly), Lovaina, entre 1480 y 1483 (Edición moderna de Buron, 1922). El libro, en posesión de Colón y anotado por él, contiene textos de Aristóteles y Platón confrontados con los textos sagrados. Historia rerum ubique gestarum, Venecia, 1477, es una enciclopedia histórica y cosmográfica que también estuvo en posesión de Colón y contiene anotaciones de su mano y letra. Il Millione, 1298. Travels, 1356. De Madariaga menciona la influencia de Mandeville (Cipango, Cathay) en la imaginación de Colón; Ballesteros Beretta asegura que el libro de Mandeville se perdió, pero que Colón lo manejó con asiduidad (1945, tomo I: 495). Livre du chemin de lonc estude, escrito entre 1402 y 1403. (Edición moderna de 1973, de J.B. Eagle). Sobre De Pisan y Mandeville, consúltese Toynbee (1892: 228 y ss.). Según Cioranescu, Colón era mucho más culto de lo que se suele admitir y se le puede considerar como un verdadero humanista. 
mujeres. De Pisan relata (PA: 42), también, un viaje imaginario y describe todos los lugares que Mandeville consideraba inaccesibles, como es el caso de los cuatro ríos del Paraíso que tenían su fuente en el Edén. "Educado en estas lecturas", señala Alfonso Reyes, "Colón emprende el viaje, y no es extraño que, en su espíritu, las visiones fabulosas ocupen muchas veces el lugar de las realidades [...]" (PA: 43).

Volviendo sobre el argumento de transitividad, hemos visto, pues, cómo los relatos míticos de carácter utópico, nacidos en el seno de la cultura grecorromana (A), estimularon, a través de los humanistas (B), a los viajeros, en general, y a Colón, en particular, hacia la búsqueda de nuevas tierras desconocidas $(\mathrm{C})$, en las cuales encontrar un referente real para esas fabulosas leyendas de riqueza y felicidad.

El argumento de la transitividad es sólo la primera parte de la justificación que Reyes prevé de su definición utópica de América. A ello, añadirá, el mexicano, otro razonamiento que ofrece notables semejanzas con el argumento de simetría conocido, también, como de reciprocidad (Perelman 1994, $\$ \$ 53$, 343 y ss.). A este respecto, cabe indicar que una relación es simétrica cuando su conversa es idéntica, esto es, cuando existe la misma relación entre B y A que entre A y B. Entre los relatos utópicos y América, ya lo hemos visto, se establecería una relación causal, dado que, a juicio de Reyes, las narraciones fantásticas estimularon los viajes que acabaron con el Descubrimiento de América. Pero sucede que, también, la relación inversa se cumple, esto es, el Descubrimiento de América supuso una renovación radical del pensamiento utópico ${ }^{15}$.

Don Alfonso argumenta (PA: 58), de hecho, que la influencia del Descubrimiento en la creación de nuevos relatos fantásticos en la Europa de los siglos XVI y XVII no es menos importante que la relación inversa que acabamos de comentar. En efecto, el hallazgo del Nuevo Mundo causó una conmoción tal en Europa que a raíz del Descubrimiento se incrementó, considerablemente, la publicación de nuevas narraciones utópicas. Estos relatos, entre los cuales Reyes enumera una serie de ejemplos, ponen de manifiesto, asimismo, la renovación de la mentalidad europea, en tanto que, a través de ellos, los humanistas confirman y desarrollan la imagen ideal de América como un reino de felicidad y fortuna ${ }^{16}$.

${ }^{15}$ Perelman $(1994$, $\$ \$ 53$ y 344) señala que el argumento de reciprocidad se basa en los nexos entre el antecedente y el consecuente de un mismo hecho (en el caso concreto que nos ocupa: el Descubrimiento de América).

${ }^{16}$ Perelman explica que los ejemplos, a fin de corresponder a la calidad de prueba, deben constituir hechos no susceptibles de duda. Además, tienen que ser numerosos y distintos entre sí, para, así, poder demostrar que las diferencias no dañan el principio general. 
Erasmo, señala Reyes, recoge la idea de la utopía en Elogio de la locura (1511); Moro, por su parte, escribe Utopía (1516), libro que se vincula, claramente, con el Descubrimiento de América, ya que el narrador es marinero y compañero de Vespucio ${ }^{17}$. En Pantagruel y Gargantúa de Rabelais, la princesa Babedec es hija del rey de los Amaurodes (los utópicos de Moro) y la carta de Gargantúa a su hijo es enviada desde Utopía, sin olvidar que el comportamiento de aquél se muestra contrario a las reglas de la vida monástica ${ }^{18}$. Entre los ensayos de Montaigne, merece especial atención el titulado "Des cannibales" (I, 31), una defensa de las costumbres, no tan bárbaras como cabría pensar, de una tribu brasileña. Tasso, a su vez, describe las clásicas Islas Felices, en los cantos XV y XVI de Gerusalemme deliberata ${ }^{19}$. El autor mexicano menciona, también, la utopía de Bacon, titulada La Nueva Atlántida ${ }^{20}$ y la de Tomás Campanella, que recibe el nombre de La ciudad del Soll. Una vez más, la tradición literaria de Europa sirve a Reyes como base para justificar su definición utópica de América.

Sin embargo, el mexicano no se limita a citar libros sobre la utopía, para probar el destino mítico de América, sino que también ilustra su argumentación (PA: 58) con ejemplos tomados de la realidad. Así, América fue el refugio de perseguidos y un terreno propicio para proyectos utópicos del catolicismo. A modo de ejemplo, Reyes recuerda las fundaciones mexicanas del obispo de Michoacán, Vasco de Quiroga, y el proyecto jesuítico de Paraguay ${ }^{22}$.

Volviendo sobre la relación de reciprocidad que se establece entre América y las narraciones utópicas, convendremos, con Perelman, en que el argumento de simetría permite hacer hincapié en el motivo mismo de la reciprocidad, en este caso la utopía. En efecto, merced a la recíproca relación entre América y los relatos utópicos, Reyes se ve autorizado a conceder una notable importancia al concepto mismo de "utopía" como base para su definición del continente americano. Al final de su ensayo, pues, don Alfonso reitera esa definición

${ }^{17}$ Sobre la relación estrecha entre el pensamiento utópico de Erasmo y de Moro, ver Philips 1981: 90-91. Edición moderna del libro de Moro de Andrews, s.d. Sobre el erasmismo español del que se derivó hacia América una corriente de esperanza, consúltese la obra fundamental de Bataillon (1966: 807-831), Apéndice "Erasmo y el Nuevo Mundo".

${ }^{18}$ Pantagruel, 1532. Gargantúa, 1534. Ver "Las Canarias y las Indias en Rabelais" de Cioranescu (1967: 89-105), sobre la idea del buen salvaje en Gargantúa y Pantagruel. Lapouge, 1973: 138-139.

${ }^{19} 1581$.

${ }^{20} 1627$. Edición moderna de Andrews, s.d.: 235-272.

${ }^{21} 1623$. Edición moderna de Andrews, s.d.: 273-317.

${ }^{22}$ Véase Lapouge, 1973: 148-151, sobre el proyecto de Ignacio de Loyola en Paraguay. Sobre Michoacán, véase Baudot 1983: 387-430. 
del Nuevo Mundo que constituyó la tesis defendida en su exposición de "El presagio de América": "O éste es el sentido de la historia, o en la historia no hay sentido alguno. [...] La declinación de nuestra América es segura como la de un astro. Empezó siendo un ideal y sigue siendo un ideal. América es una Utopía” (PA: 60).

Cuando consideramos la interpretación histórica de Reyes sobre el Descubrimiento, percepción que va a determinar su posterior definición de América, varios aspectos merecen ser destacados. En primer lugar, la tesis sostenida por los primeros historiadores del Descubrimiento, según la cual Colón pensaba descubrir un mundo desconocido, contradice la creencia, hoy generalmente aceptada, de que el genovés se interesaba por encontrar una nueva ruta hacia el Oriente ${ }^{23}$. Según esta versión de la historia, fue Martín Alonso Pinzón quien le había aconsejado que no hablase más de sus nuevas tierras ni de Antilia y que insistiera en la nueva ruta para el Asia (Cipango, Cathay), si quería reclutar gente para su empresa y no perder su valimiento en la corte. Reyes es consciente de esta discrepancia entre su versión de los hechos y la tesis de los historiadores más recientes y advierte que, puesto que se trata de una "hipótesis", conviene exponerla "objetivamente y sin juzgarla". Sin embargo, podemos deducir más de una vez la preferencia del autor por una hipótesis concreta, por ejemplo, cuando se pregunta: "Así concebido el Descubrimiento, como un duelo trascendental entre el Japón y Haití, el Cipango y la Antilia, donde la Antilia se disfraza de Cipango para mejor triunfar; como una disputa semigeográfica o semifabulosa entre Pinzón y Colón, a bordo de unas carabelas y en mitad de un mar desconocido, ¿no adquiere en verdad mayor patetismo?” (PA: 35 ).

Esta hipótesis, según la cual la ruta comercial hacia el Oriente no era el verdadero objetivo del descubridor, le permite a Reyes (PA: 41) establecer una nítida distinción entre Colón y otros marinos, de los que afirma que sólo eran mercaderes impulsados por el afán de obtener riquezas y fama terrenal, mientras que el genovés era un descubridor animado por el espíritu del Humanismo. Con todo, otras fuentes, según las cuales Colón -pese a su rico y vasto imaginario- se interesó, sobre todo, por los beneficios de su viaje -a fin de cuentas, un proyecto comercial-, contradicen el punto de vista defendido por el ensayista ${ }^{24}$. El propio Reyes menciona la siguiente objeción del historiador

${ }^{23}$ Por lo general, todos los colombistas admiten hoy día la llamada versión asiática del Descubrimiento. En este siglo, y como casos excepcionales, Vignaud (1911) y Rómulo Carbia sostienen, todavía, que el verdadero propósito de Colón era encontrar una o varias islas desconocidas, un nuevo mundo, y que no salió en búsqueda de un camino marítimo que le llevara al Oriente.

${ }^{24}$ Véase Pastor 1983: 30, 84, 85. 
Salvador de Madariaga a su tesis: Colón manifiesta, en sus notas marginales al Imago Mundi del cardenal Aliaco, mayor interés por joyas, piedras preciosas u otros artículos de valor comercial que por referencias a monstruos y fábulas. Sin embargo, Reyes prefiere hacer hincapié en el hecho, subrayado también por el propio Madariaga, de que Colón, "a medida que adelanta en sus exploraciones americanas, se va dejando embriagar por lo fabuloso" (PA: 13). Una vez más, y por lo que respecta a los factores que determinan el Descubrimiento, el ensayista mexicano opta por minimizar el aspecto "materialista" en beneficio de las motivaciones espirituales.

Resulta evidente que las exploraciones de los europeos constituyen para el ensayista mexicano, sobre todo, una empresa espiritual, el resultado de un impulso místico ${ }^{25}$ en busca de unos mitos inexistentes y, sólo en un segundo término, reconoce, en dichos viajes, una voluntad alentada por los intereses económicos o científico-geográficos. Esta idea -históricamente muy discutible por no decir incorrecta- constituye la base sobre la que se apoya toda la argumentación de "El presagio de América". De hecho, si no se aceptara este punto de partida, el razonamiento que sostiene la definición utópica de América se vendría abajo, dado que es precisamente el interés de los europeos por un mundo mejor lo que confiere a América su identidad, una identidad que constituye, al tiempo, un proyecto para el futuro: la utopía.

Al margen de las intenciones de los primeros exploradores del Nuevo Mundo, llama la atención la gran importancia concedida a la literatura, y más concretamente a la tradición literaria europea, en la visión de Reyes sobre el Descubrimiento. En efecto, son los mitos clásicos europeos que preceden al Descubrimiento los que constituyen la tradición literaria sobre la que se apoya el ensayista mexicano para justificar su definición de América; igualmente, los relatos utópicos escritos a raíz del Descubrimiento pertenecen a la tradición europea y son utilizados por el autor en favor de su argumentación. Resumiendo puede decirse que, en su búsqueda de los factores que impulsaron el Descubrimiento del Nuevo Mundo, y que determinarán el sentido de América, Reyes remite a las narraciones míticas acerca de la existencia de un paraíso en la tierra

${ }^{25}$ El propio Reyes utiliza este término "místico" en el ensayo "Atenea política” (Tentativas y orientaciones, O.C. t. XI: 190) con respecto a la colonización de Hispanoamérica. En este texto, clasifica el imperialismo ibérico no bajo los imperialismos económicos, sino que lo describe como "un caso mixto", una "mezcla de codicia y gloria, de religión y hazaña”. Milhou (1983: 474), sin embargo, señala que la codicia es más propia de Colón que la religión: "Devoto y con ribetes de misticismo, preocupado por la moralidad de los expedicionarios que capitaneaba, manifestaba Colón una codicia y sobre todo un sentido de los honores debidos a su persona providencial, fundadora de un linaje elegido, poco conformes con la imagen de seglar piadoso que quería dar de sí mismo”. 
que se remontan a la Antigüedad Clásica y continúan circulando a lo largo y ancho de la Europa medieval. Esta tesis se verá reforzada por la asociación posterior de América con una nueva novela utópica, género que conoce, en la literatura europea, un primer auge durante el Renacimiento para florecer de nuevo, con mayor vigor si cabe, en pleno siglo XIX.

Ambos aspectos que acabamos de explicar, tanto las intenciones "místicas" del descubridor como la tradición literaria europea, son elementos europeos. En consecuencia, no es exagerado afirmar que Reyes funda su argumentación en favor de la definición de América exclusivamente sobre aspectos europeos, ya sea la propia literatura nacida en la Vieja Europa, ya sea el proyecto de una tierra desconocida y paradisíaca que Colón tenía en la cabeza, a juicio de Reyes, antes de partir. Este alto grado de autoridad concedido a lo europeo por lo que a la cuestión de la identidad americana se refiere, es muy corriente en los ensayos de Alfonso Reyes, quien considera imprescindible dominar la tradición literaria europea relacionada con la utopía para realizarla y alcanzar, de este modo, lo auténticamente americano.

En América como conciencia, Zea (1983: 58) opina, en este sentido, que el fracaso del ser americano reside precisamente en ese empeño por realizar lo que no le es propio, ese empeñamiento en convertirse en utopía europea, ese negarse a ser americano. De esta primera idealización utópica de América, y, más concretamente, del choque de la realidad con el ideal, surgirá, según Zea, la problemática de la valorización de América por el europeo y la autovalorización de América por el propio americano.

\section{CONCLUSIONES}

Existe un rasgo de "El presagio de América" que no ha dejado de llamar nuestra atención a lo largo de este análisis: la relación entre forma y fondo. Efectivamente, la rigidez subyacente a la argumentación no se deja adivinar, en absoluto, durante la lectura del ensayo. Consideramos demostrado que Reyes se sirve, en esta defensa de la identidad utópica de América, de un razonamiento bien construido y cuyos procedimientos principales se pueden reducir, en grandes líneas, a los esquemas de transitividad y de reciprocidad, tal y como Perelman los describe. Ahora bien, la rigidez y el equilibrio subyacentes a la argumentación no se dejan adivinar, fácilmente, durante la lectura del ensayo. Por el contrario, diversas estrategias textuales -entre las cuales algunas pertenecen al lenguaje ficcional- ocultan la orientación firme e inequívoca del ensayo. Figuras estilísticas, anécdotas divertidas, divagaciones, narraciones, descripciones, comentarios eruditos, citas poéticas, bromas, e, inclusive, una 
pequeña "comedieta", al margen de la forma fragmentada en 21 capítulos, amenizan la lectura y hacen que la argumentación central parezca menos trascendente, al tiempo que eliminan lo que podría llegar a ser una molesta intención persuasiva demasiado obvia. De no hacer hincapié en este aspecto, nuestro análisis ofrecería una imagen falsa de "El presagio de América", ensayo que, como hemos visto, no se reduce a meros esquemas argumentativos racionales en favor de la identidad utópica de América.

El hecho de que los argumentos racionales se escondan bajo una apariencia literaria tan exquisitamente elaborada, desde el punto de vista estilístico, revela que los argumentos realmente substanciales del ensayo no se hallan en la perfección del argumento de la transitividad o de la simetría, sino, precisamente, en los aspectos formales que sustentan esta argumentación: los efectos de la belleza estilística, el encanto de la narración ficticia, el toque de fantasía... Así, pues, cabe concluir que Reyes busca persuadir, emocionalmente, al lector de su interpretación del suceso histórico. La argumentación de Alfonso Reyes se construye sobre postulados estéticos y afectivos tanto como sobre pruebas lógicas; combina res y verba, inventio y elocutio, como dos estrategias argumentativas complementarias para, así, lograr la persuasión.

\section{OBRAS CITADAS}

Ailly, Pierre d'. 1930. Imago mundi. Paris: Maisonneuve frères.

Aínsa, Fernando. 1987. "Séneca y América. Análisis de un presentimiento literario", en Cuadernos Hispanoamericanos. Madrid, vol. 442: 7-26.

Andrews, Charles M. (ed.). s.d. Famous Utopias. Rousseau's Social Contract, Morés Utopia, Bacon's New Atlantis, Campanella's City of the Sun. New York: Tudor.

Arciniegas, Germán. 1975. América en Europa. Buenos Aires: Editorial Sudamericana. Babcock, William H. 1922. Legendary islands of the Atlantic. New York: American Geographical Society.

Ballesteros Beretta, Antonio. 1945. Cristóbal Colón y el descubrimiento de América, Tomos IV y V en Historia de América. Barcelona-Buenos Aires: Salvat.

Bataillon, Marcel. 1955. Dos concepciones de la tarea histórica, con motivo de la idea del Descubrimiento de América. México: Imprenta Universitaria.

Baudot, Georges. 1983. "La relación de Michoacán". Utopía e historia en México. Trad. del francés por V.G. Loscertales. Madrid: Espasa-Calpe: 387-427.

Cioranescu, Alejandro. 1967. Colón, humanista. Madrid: Editorial Prensa Española. Fernández Retamar, Roberto. 1989. "América, descubrimiento, diálogos". Heinz Dieterich (comp.) Nuestra América contra el V Centenario. Navarro: Txalaparta Editorial: 87-100.

France, Anatole. 1994. La Isla de los Pingüinos, trad. y notas de Jorge Carrier Vélez. Barcelona: Edicomunicaciones. 
Gil, Juan. 1989. Mitos y utopias del Descubrimiento. Madrid: Alianza Universal.

Lapouge, Gilles. 1973. Utopie et civilisations. Genève: Weber.

Milhou, Alain. 1983. Colón y su mentalidad mesiánica. Valladolid: Casa-Museo de Colón.

O’Gorman, Edmundo. 1984. La invención de América. México: Fondo de Cultura Económica.

Pastor, Beatriz. 1983. Discursos narrativos de la conquista de América. La Habana: Casa de las Américas.

Penrose, Boies. 1960. Travel and discovery in the Renaissance 1420 - 1620. Cambridge - Massachusetts: Harvard University Press.

Perelman, Chaïm y Olbrechts-Tyteca, L. 1994. Tratado de la argumentación, trad. por J. Sevilla Muñoz. Madrid: Gredos.

Pisan, Christine de. 1973. Livre du chemin de lonc estude. University of Georgia: P.B. Eagle. Platón. 1966. Timaeus, Critias, Cleitophon, Menexenus, Epistles, trad. por R.G. Bury. London-Cambridge-Massachusetts: William Heinemann-Harvard University Press.

Ramos, Demetrio. 1972. Los contactos transatlánticos decisivos como precedentes del viaje de Colón. Universidad de Valladolid: Casa-Museo de Colón.

Séneca. 1953. Seneca's tragedies, Vol. 1 Hercules Furens, Troades, Medea, Hippolytus, Oedipus, trad. por F.J. Miller. London-Cambridge-Massachusetts: William HeinemannHarvard University Press.

Toynbee, Paget. 1892. "Christine de Pisan and Sir John Mandeville" en Romania, tome XXI, Paris: 228 y ss.

In this article, we focus on Alfonso Reyes' essay "El presagio de América", paying special attention to the standpoint of the Mexican essayist in the historical debate about the Discovery of America. We will conclude from the results of our rhetorical analysis that Reyes defends the utopian identity of the New World. Schematically, his argumentation can be reduced to two rhetoric systems (transitivity and reciprocity) as Perelman de-scribes them. Nevertheless, several textual strategies hide the rigidity and firm orienta-tion 